To the Editors:

\title{
Correlation between the steroid receptor status and Her 2 neu amplification of primary breast carcinoma and lymph node metastases: a retrospective analysis
}

\author{
Ceylon Medical Journal 2011; 56: 131-132
}

Carcinoma of breast is a common cancer in women. Prognosis of breast carcinoma is assessed using steroid receptor status and Her 2 neu amplification. Steroid receptors, when present denotes a favourable clinical outcome and has also been used to determine whether a patient benefits from adjuvant therapy [1]. Her 2 neu amplification is associated with a poor prognosis [2]. Furthermore, Her 2 neu amplification is negatively associated with steroid receptor expression in breast carcinoma [3]. Routinely, the primary tumour is examined for the assessment of oestrogen and progesterone receptor status (ER, PR) and amplification of Her 2 neu. However there are instances where the primary tumour is not available or unsatisfactory (due to autolysis) for assessment. Lymph node metastases could be evaluated in these circumstances. The aim of this study was to assess the correlation and concordance of ER, PR status and Her 2 neu amplification between the primary tumour and the lymph node metastases in order to determine if lymph node metastases could be used as a source of tissue for such assessment.

Samples of invasive ductal carcinoma and the lymph node metastases belonging to 27 mastectomy specimens were retrieved. They were assessed for the ER, PR status and Her 2 neu amplification simultaneously using a three step Strept ABC system. ER and PR score were assessed using the quick (Allred) score. Her 2 neu amplification was assessed according to the Royal College of Pathologists recommended semi quantitative method. The correlation and the difference of the ER, PR receptor status and Her 2 neu amplification in the primary and the metastatic tumour were analysed using Spearmans rank correlation and Wilcoxon signed rank test respectively (Table 1,2 and 3).

Table 1. Distribution of oestrogen receptors

\begin{tabular}{llccc}
\hline & & \multicolumn{3}{c}{ Primarytumour ER } \\
\cline { 3 - 5 } & & positive & negative & total \\
\hline Lymph node & positive & 19 & 1 & 20 \\
metastases & negative & 1 & 6 & 7 \\
ER & total & 20 & 7 & 27 \\
\hline
\end{tabular}

Table 2. Distribution of progesterone receptors

\begin{tabular}{llccc}
\hline & & \multicolumn{3}{c}{ Primary tumour PR } \\
\cline { 3 - 5 } & & positive & negative & total \\
\hline Lymph node & positive & 16 & 1 & 17 \\
metastases & negative & 1 & 9 & 10 \\
PR & total & 17 & 10 & 27 \\
\hline
\end{tabular}




\section{Table 3. Distribution of Her 2 neu in primary tumour and lymph node metastases}

\begin{tabular}{llccc}
\hline & & \multicolumn{3}{c}{ Primary tumour Her 2neu } \\
\cline { 3 - 5 } & & positive & Negative & total \\
\hline Lymph node & positive & 7 & 3 & 10 \\
metastases & negative & 1 & 16 & 17 \\
Her 2neu & total & 8 & 19 & 27 \\
\hline
\end{tabular}

The positive correlation seen in the ER, PR scores and Her 2 neu amplification between the primary tumour and lymph node metastases and the absence of a significant difference between the score of ER, PR and the amplification of Her 2 neu between the primary tumour and the lymph node metastases indicates that there is a concordance in these parameters between the primary tumour and its nodal metastases. Hence assessment of ER, PR status and Her 2 neu amplification in nodal metastases is accurate and useful when the primary tumour is unavailable for study since the ER, PR score and the expression of Her 2 neu amplification of the nodal metastases is similar to that of the primary tumor in breast carcinoma of Sri Lankans.

\section{References}

1. Pyene SJL, Bowen RL, Jones JL, Wells LA. Predictive markers in breast cancer - the present. Histopathology 2008; 52: 82-90.

2. Tsuda H, Hiroshani S, Shimosato Y, et al. Correlation between histologic grade of malignancy and copy number of c-erb B-2gene in breast carcinoma. Cancer 1990; 65: 1794-800.

3. Umekita Y, Sagara Y, Yoshida H. Estrogen receptor mutations and changes in estrogen receptor and progesterone receptor protein expression in metastatic and recurrent breast cancer. Japanese Journal of Cancer 1998; 89: 27-32.

\section{U Dissanayake ${ }^{1}$, N V I Ratnatunga ${ }^{1}$}

${ }^{1}$ Department of Pathology, Faculty of Medicine, University of Peradeniya, Sri Lanka.

Correspondence: IUD, e-mail: <udirani@gmail.com>. Received 12 October 2010 and revised version accepted 24 March 2011. Competing interests: none declared. 